\title{
Notes
}

\section{Color Tuning of Perylene Based Lyotropic Chromonic Liquid Crystal}

\author{
Jaishri J. Naidu, Yun Ju Bae, Kwang-Un Jeong, Seunghan Shin, ${ }^{\dagger}$ and Myong-Hoon Lee ${ }^{*}$ \\ Department of Polymer. Nano Science and Technologv, Chonbuk National Chiversitv, Chonju, Chonbuk 561-756, Korea \\ ${ }^{\star}$ E-mail: mhlee2ochonbukac.kr \\ tKorea Institute of Industrial Technologv (KITECH), Chonan, Chungnam 330-825, Korea \\ Received September 16, 2008, Accepted Nowember 11, 2008
}

Key Words: Perylenebis(dicarboximides), Lyotropic cluromonic liquid crystal, Color tuning

Perylene bisimides (PBIs) are widely used as dyes and pigments since they show outstanding chemical. thernal and photochemical stability. Compared to other dyes and pigments. PBIs have advantages such as better solubility. synthetic simplicity. and less trouble in purification Beside the conventional uses. PBIs are key chromophores for high-tech applications such as re-

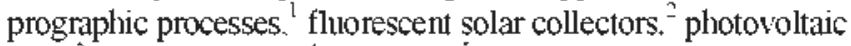
cells. ${ }^{3}$ optical switches. ${ }^{+}$and lasers. ${ }^{5}$ In this context. PBIs are generally referred to as functional dyes. Especially, PBIs having ionic periphery have attracted much attention because they can form lyotropic chromonic liquid crystal (LCLC) in aqueous solution The anisotropic orientation of molecules with $\pi-\pi$ stacking of aromatic core can exploit their intrinsic properties most efficiently in the potential applications such as coatable polarizers. ${ }^{6}$ oriented optical films. and biosensors. ${ }^{8}$ In recent years. emphasis has been given on tailoring the finctional groups of PBI so that the desired optical and/or electronic properties can be achieved. In that sense and mary advantages of PBI taken into account, color tuning of PBI dye is one of the key issues especially in optical and photonic applications because most of PBIs are only red or orange colored.

Color tuning of PBI dy'e can be achieved by substitution at the bay area (1.7-position of the perylene core). Stalke $e t$ al. reported a series of compounds with different substituents at bay region of perylene core. ${ }^{5}$ Wurthner et al. also reported a series of thermotropic liquid cry stals based on PBI dyes with different substituents at the bay area ( $1.6,7.12$ positions of the perylene core). ${ }^{16}$ According to their reports, PBI derivatives with electron-donating substituents at the bay area exhibit a large bathochromic shift of the absorption maxima $\left(\partial_{\text {ax }}\right)$ compared to the unsubstituted $\mathrm{PBI}$, reflecting pronounced electronic interactions between the perylene core and the electron-donating groups in bay area. In contrast, PBI derivatives with electron-withdrawing substituents such as $\mathrm{Cl}, \mathrm{Br}$, or pentafluorophenoxy groups at the bay positions showed hypsochromic shift of $\lambda_{\max }$ with respect to that of the unsubstituted PBI.

However. structural modification of PBI having ionic peripheries for the generation of LCLC is synthetically complicated because the resulting PBI molecules often have limited solubility in common organic solvents due to their ionic nature. In addition. substitution at the bay area can cause a twisting of aromatic core possibly hindering $\pi-\pi$ stacking which is crucial for the formation of lyotropic colunmar liquid crystal. Therefore, it is challenging to design and synthesize a lyotropic liquid cry stalline PBI molecule having green or blue color. In this work. we report the first synthesis of green lyotropic liquid crystalline compound based on PBI core having py rrolidine substituent at the bay area.

Bromination of perylene dianhydride was performed according to the BASF patent. ${ }^{1]}$ The bromination under this condition afforded a mixture of 1.7- and 1,6-dibrominated compounds with trace amount of 1,6.7-tribrominated analogues (Figure 1). The resulting mixture was insoluble in organic solvents. and therefore. could not be purified by any means. The crude mixture was used for the subsequent inidization (Figure 2) with $\mathrm{N}, \mathrm{N}$-diethylethylene diamine in a nixed solvent of $\mathrm{H}_{2} \mathrm{O} / \mathrm{n}-\mathrm{PrOH}(2: 1 \mathrm{v} / \mathrm{v})$ at $80^{\circ} \mathrm{C}$. After the reaction, the product became soluble in organic solvents such as $\mathrm{CH}_{2} \mathrm{Cl}_{2}$ and chloroform, which enabled the separation of regioisomers by column chromatography. From the first chromatography. 1,6,7-tribrominated perylene bisimide was separated (in less than $1 \%$ yield) from the nuixture of 1.7 - and 1.6-dibrominated compounds. $400 \mathrm{MHz}{ }^{1} \mathrm{H}-\mathrm{NMR}$ analy sis of the residual mixture revealed a $80: 20$ ratio of the 1.7 - and 1,6 -
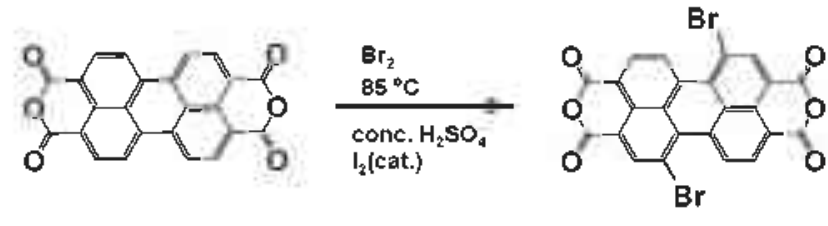

1.7-isomer

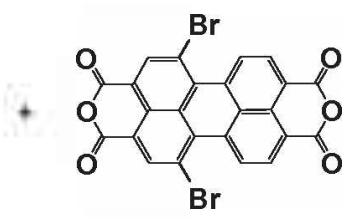

1.6-isomer

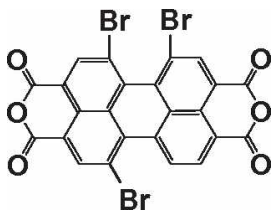

1,6.7-isomer

Figure 1. Bromination products of perylene dianlyydride 


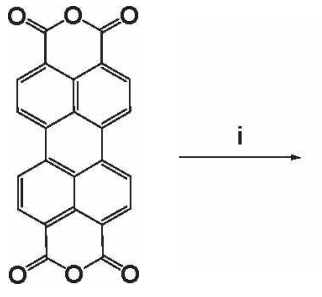

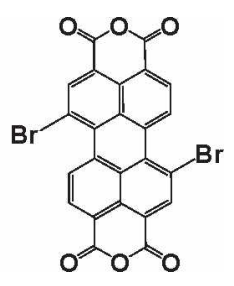

1

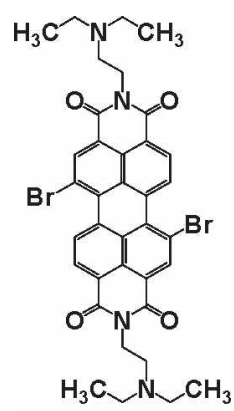

2

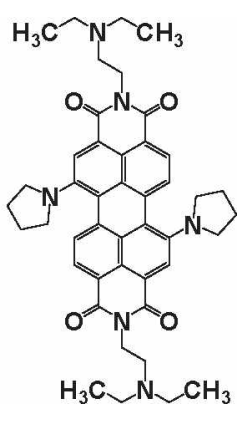

3

Figure 2. Synthesis of pyrrolidine-substituted perylene bisimide. i) $\mathrm{Br}_{2}, \mathrm{conc}_{2} \mathrm{H}_{2} \mathrm{SO}_{4} \mathrm{I}_{2}$ (cat.), $85^{\circ} \mathrm{C}, 12 \mathrm{~h}$; ii j $\mathrm{N}, \mathrm{N}$-diethylethy lene diamine, 85 ${ }^{\circ} \mathrm{C}, 12 \mathrm{~h}$; iii) pyrrolidone, $55^{\circ} \mathrm{C}, 24 \mathrm{~h}$, Ar atmosphere

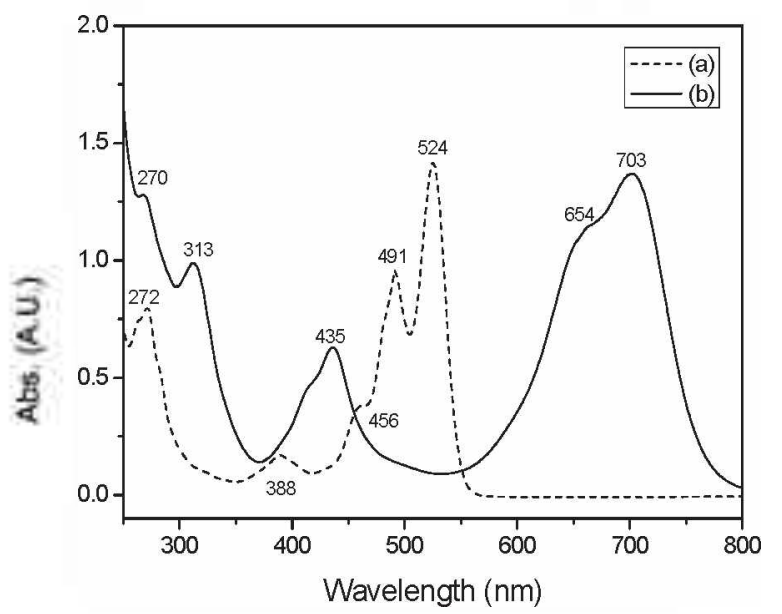

Figure 3. UV/visabsorption spectra of perylene bisimides in methanol solution: (a) bromo-substituted perylene bisimide; (b) pyrrolidine-substituted perylene bisinide

regioisomers. 1.7-Dibrominated compound (2) was separated from this mixture as a major component (in 61\% yield) after the second column chromatography. The nucleophilic substitution of 1,7-dibromoperylene bisimide with pyrrolidine according to Wasielewskis method ${ }^{12}$ afforded the corresponding 1.7-dipy rrolidiny̧lperylene bisimide (3) as a green solid in $60 \%$ yield after column chromatography. Good solubility in organic solvents and water as well as high thermal stability was observed for $N, N$-diethyl ethylenediamine 1 . 7-dipyrrolidinylperylene-3.4:9.10-tetracarboxỵlic acid bisimide (3).

The optical properties of bromo-substituted and pyrrolidine-substituted PBIs (2.3) were investigated by UV/vis spectroscopy as shown in Figure 3. Both dyes in methanol solution exhibited multiple $S_{(1-} S_{1}$ absorption bands with $\lambda_{\text {max }}$ at 524 and $703 \mathrm{~nm}$, respectively. The $\lambda_{\text {miax }}$ of bromo-substituted $\mathrm{PBI}$ was shifted only slightly from that of the unsubstituted $\mathrm{PBI}\left(\lambda_{\max }=527 \mathrm{~nm}\right.$ in $\left.\mathrm{CH}_{2} \mathrm{Cl}_{2}\right){ }^{13}$ In contrast. the $\lambda_{\max }$ of compound 3 showed a bathochromic shift by $76 \mathrm{~nm}$ with showing green color. which is mainly due to the electron-donating pyrrolidine groups directly attached to perylene core at the bay area. Additionally band shape of the compound 3 was broader than those of compound 2 or unsubstituted PBI. which is probably attributed to the loss of planarity of perylene core due to the steric hindrance at the bay area. ${ }^{\text {jic }}$ Hydrochloride
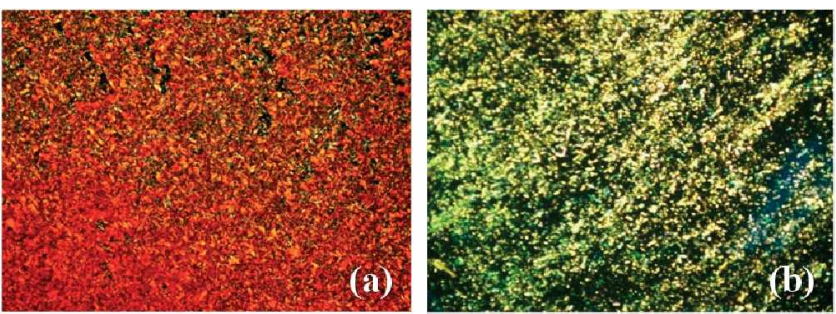

Figure 4. Optical microscopic pictures of perylene bisimides 1.0 wt\% aqueous solution) at room temperature: (a) bromo-substituted pery lene hisimide; (b) pyrrolidine-substituted pery lene bisimide

salts of compound $\mathbf{2}$ and $\mathbf{3}$ were dissolved in distilled water ( $\mathrm{I}$ $w t \%$ ). and their optical textures were examined by polarized optical microscope (POM). As depicted in Figure 4. both of solution samples exhibited typical texture of columnar phase and well-flowing behaviour confirming that the synthesized compounds are lỵotropic liquid crystals. Further characterization of liquid crystalline behavior and structural analyses including $X$-ray diffraction and phase diagram studies are now in progress. which will be published in due course.

In summary. we reported the first example of the green lyotropic chromonic liquid crystalline compound based on perylene bisimide. The color tuning of perylene bisimide was achieved by introducing electron-donating substituents at the bay area. The syntheses proceeded in good yields via a short and convenient synthetic route. This dye exhibits good thermal stability, solubility in water and organic solvents as well. The structure was characterized by ${ }^{1} \mathrm{H}-\mathrm{NMR}$. ${ }^{13} \mathrm{C}-\mathrm{NMR}$, nass. and UV/Vis spectroscopies. Aqueous solution of hydrochloride salt exhibited lyotropic chromonic liquid crystalline columnar phase at room temperature examined by polarized optical microscopy.

\section{Experimental Section}

$N, N$-Diethylethylenediamine 1,7-bromoperylene-3,4:9,10tetracarboxylic acid bisimide (2). A nixture of perylene$3.4: 9.10$-tetracarboxylic acid anlydride $(15.65 \mathrm{~g} .80 .0 \mathrm{mmol})$ and conc. sulfuric acid ( $236 \mathrm{~g}$ ) was stirred for $12 \mathrm{~h}$ at room temperature. and subsequestly. $0.385 \mathrm{~g}$ of $\mathrm{I}_{2}(3.0 \mathrm{mmnol})$ was added. The reaction mixture was heated to $85^{\circ} \mathrm{C}$. and bromine ( $14.1 \mathrm{~g} .176 \mathrm{~nm}$ ol) was added dropwise over a time period of $8 \mathrm{~h}$. After bromine addition. the reaction mixture was heated 
for an additional $10 \mathrm{~h}$ at $85^{\circ} \mathrm{C}$, and cooled to room temperature. The excess bromine was removed by a gentle stream of $\mathrm{N}_{z}$ gas. and $32.5 \mathrm{ml}$ of distilled water was added carefully. The resulting precipitate was separated by filtration through a G4 funnel. washed with $86 \%$ sulfuric acid $(150 \mathrm{ml})$ and large amount of distilled water. and dried in a vacuum to give a crude mixture of 1.7- and 1.6-dibromo- and 1.7.6-tribromoPBls. The solid was dried under vacuum to obtain isomeric mixture of compound 1 in $89.4 \%$ yield. A suspension of above mixture $(0.95 \mathrm{~g} .1 .72 \mathrm{mmol})$. N. N-diethylethylene diamine $(0.502 \mathrm{~g} .5 .07 \mathrm{mmol})$. and acetic acid $(0.50 \mathrm{~g}, 8.33 \mathrm{mmol})$ in $20 \mathrm{ml}$ of $2: 1$ mixture of $\mathrm{H}_{2} \mathrm{O} / \mathrm{n}-\mathrm{PrOH}(\mathrm{v} / \mathrm{v})$ was stirred at $85^{\circ} \mathrm{C}$ under Ar atmosphere for $8 \mathrm{~h}$. After the mixture was cooled to room temperature the precipitate was separated by filtration. washed with $100 \mathrm{ml}$ of methanol and dried in a vacuum. The crude product was purified by silica gel column chromatography with $\mathrm{CH}_{2} \mathrm{Cl}_{2}$ as eluent to give a red powder $(750 \mathrm{mg}$. $61 \%$ ) which was a regioisomeric mixture of $1.7-$ and 1,6 -dibromo PBIs with $80: 20$ ratio as revealed by $400 \mathrm{MHz}{ }^{\mathrm{l}} \mathrm{H}-\mathrm{NMR}$ analy ses. Second column chromatography gave a pure 1.7-dibromo compound 2 which was confinned by ${ }^{1} \mathrm{H}$ - and ${ }^{13} \mathrm{C}-\mathrm{NMR}$ spectra and mass spectroscopy. ${ }^{1} \mathrm{H}-\mathrm{NMR}$ ( $400 \mathrm{MHz}$ in $\mathrm{CDCl}_{3}$ ): $\delta$ (ppm) 9.4 (d. $2 \mathrm{H} . J=8.1 \mathrm{~Hz}$ ), 8.9 (s. $2 \mathrm{H}$ ). 8.6 (d. $2 \mathrm{H} . J=8.1$ $\mathrm{Hz})+.3(\mathrm{t} .6 \mathrm{H}) .2 .8(\mathrm{t} .6 \mathrm{H}), 2.6(\mathrm{q} .16 \mathrm{H}) .1 .1(\mathrm{t} .12 \mathrm{H}),{ }^{13} \mathrm{C}-\mathrm{NMR}$ $\left(400 \mathrm{MHz}\right.$, in $\left.\mathrm{CDCl}_{3}\right): \delta$ (ppm) 159.4. 136.2. 133.0, 132.0 . $130.9,130.7,129.2,128.5,128.1,124.0,123.8,50.2,49.2$. 47.7. 13.3; MS (EI, 70 eV) m/z: 746.09; UV/vis (in methanol): Mnax: $388.456 .491,524(\mathrm{~mm})$.

$N, N$-Diethylethylenediamine 1,7-dipy molidinylperylene3,4:9,10-tetracanboxylic acid bisimide (3). A mixture of 1.7dibromo PBI (2) (95.0 mg. $0.133 \mathrm{~mol})$ and pyrrolidine ( $4.30 \mathrm{~g}$. $59.7 \mathrm{mmol}$ ) was stirred for $24 \mathrm{~h}$ at $55^{\circ} \mathrm{C}$ (external. oil bath) under Ar atmosphere. Subsequently the reaction mixture was poured into $15 \mathrm{ml}$ of $12 \% \mathrm{HCl}$ with stirring. The solution mixture was extracted with methylene chloride $(3 \times 20 \mathrm{ml})$. dried over $\mathrm{MgSO}_{4}$. and concentrated by rotary evaporation. The resulting solid was purified by column chromatograply on silica gel with $\mathrm{CH}_{2} \mathrm{Cl}_{2} /$ hexane $(40: \mathrm{l}$. v/v) as eluent to yield $62 \mathrm{mg}$ $(50 \%)$ of a green solid. ${ }^{1} \mathrm{H}-\mathrm{NMR}\left(400 \mathrm{MHz}\right.$ in $\left.\mathrm{CDCl}_{3}\right) ; \delta$ (ppm) 8.38-8.34 (d, 2H, $J=8.1 \mathrm{~Hz}) .8 .32$ (s. $2 \mathrm{H}), 7.5-7.4(\mathrm{~d}$. $2 \mathrm{H} . J=8.1 \mathrm{~Hz}) .+52(\mathrm{t} .3 \mathrm{H}), 3.67(\mathrm{t} .3 \mathrm{H}), 3.2(\mathrm{t} .3 \mathrm{H}), 3.0(\mathrm{t}$. $4 \mathrm{H}) .1 .9(\mathrm{~m} .5 \mathrm{H}) .1 .4 \mathrm{l}(\mathrm{t}, 3 \mathrm{H}) ;{ }^{13} \mathrm{C}-\mathrm{NMR}\left(100 \mathrm{MHz}, \mathrm{CDCl}_{3}\right): \delta$ (ppm) 159.4. 152.9. 134.3, 133.0, 131.5, 130.9, 128.3, 127.7 . $122.2,119.9,118.0 .52 .2,49.2 .47 .7,25.5 .13 .3: \mathrm{MS}(\mathrm{EI}, 70$ eV) $m / z:[\mathrm{M}+]$ 726.39: UV/sis (in methanol): $i$ max: $416,435$. $65+.703(\mathrm{~nm})$.
Hydrochloride salt of compound 3 was prepared by completely dissolving compound 3 in conc. $\mathrm{HCl}$, with subsequent evaporation of remaining $\mathrm{HCl}$ by rotary evaporator under reduced pressure. The resulting solid was dried in vacuum oven at room temperature for $2+\mathrm{h}$.

Acknowledgments. This study was supported by a grant from the Fundamental R\&D Program for Core Technology of Materials funded by the Ministry of Commerce. Industry and Energy. Republic of Korea. JJN acknowledges for the financial support by grant of the Post-doc Progrant. Chonbuk National University 2007. YJB also thank to Polymer BIN Fusion Research Center at Chonbuk National University

\section{References}

1. Loufty, H. O.: Hor, A. M.; Kazmaler, P.: Tarn, M. J. Imag. Sci. $1989,33,151$.

2. (a) Seybold, G.; Wagenblast, G. Dyes Pigm 1989, 11, 303. (b) Langhals, H. Nachr Chem. Technol. Lab. 1980, 28, 716.

3. Schlettwein, D; Wohrle, D.; Kamann, E.; Melville, U, Chem. Mater: $1994,6,3$.

4. ONeil, M. P. Niemczyk, M. P.: Svec, W. A.: Gosztola, D.; Gaines, G. L.; Wasielewski, M. R. Science 1992, 257,63.

5. (a) Sadrai, M.: Hadel, L.; Samers, R. R.; Husain, S.; Kroghlespersen, K. Westbrook, J. D; Bird, G. R. J. Phys. Chent 1992, 96, 7988. (b) Gvishi, R.; Reisteld, R.; Burshtein, Z. Chen. Phys. Letr. 1993, 213, 338

6. (a) Iverson, 1. K: Tam-Chang, S.-W. J. An. Chem. Soc. 1999 , 121, 5801. (b) Iverson, I. K ; Casey, S. M.; Seo, W; Tam-Chang. S.-W; Hindzola, B. A. Langmmin 2002, 18, 3510.

7. Tam-Chang, S.-W; Seo, W.; Iverson, I. K.; Casey, S. M. Angew. Chem., Int Ed. 2003, 12,897

8. (a) Shiyanovskii, S. V; Lavrentovich, O. D.; Schneider, T:; Ishikawa, T.; Smalyukh, I. I.; Woolverton, C. I.; Niehaus, G. D.; Doane, K. J A Hol Coust Liq. Crust 2005, 134, 587. (b) Shiyanovskii, S. V: Schneider, T.; Smalyukh, I. I.: Ishikawa, T.: Niehaus, G. D.; Doanle, K. J : Woolverton, C. J : Lavrentovich, O. D. Phys. Rev E 2005, 71, 020702R. (c) Woolverton, C. J : Gustely, E; Li, L.: Lavrentovich, O. D. Liq. Crvst. 2005, $32,417$.

9. Wurthner, F.; Stepanenko, V; Chen, Z; Saha-Moller, C. R:; Kocher, N.; Stalke, D. J. Uig. Chem. 2004, 69,7933.

10. Chen, Z, Baumeister, U; Tschierske, C, Wurthner, F. Chem. Eur. J. 2007, 13,450

11. Bolum, A.; Arms, H.; Henning, G.: Blaschka, P. (BASF AG) Geman Pat. DE 19547209 A I, 1997; Chent. Abstr: 1997, 127, $96569 \mathrm{~g}$.

12. Zhao, Y.: Wasielewski, M. R. Tetrahedron Lett. 1999, $40,7047$.

13. (a) Wurthner, F; Chen, Z.; Dehm, V; Stepanenko, V. Chem. Conmm. 2006, 1188. b) Chen, Z.; Stepanenko, V: Dehm, V: Prins, P.: Siebbeles, L. D. A.; Seibt, J.: Marquetand, P.: Engel, V; Wurthner, F. Chem. Eur, J. 2006, 12,436. 